Research Article

\title{
Constitutive Model of 15 Propellant considering the Confining Pressure Effect
}

\author{
Tianpeng Li, ${ }^{1,2}$ Junli Han $\mathbb{D}^{1},{ }^{1,3}$ Shixin Wang, ${ }^{4}$ Yong He, ${ }^{1}$ Xiong Chen, ${ }^{1}$ and Bang $\mathrm{Lu}^{2}$ \\ ${ }^{1}$ Nanjing University of Science and Technology, Nanjing 210094, China \\ ${ }^{2}$ Army Engineering University of PLA, Shijiazhuang 050003, China \\ ${ }^{3}$ Beijing Institute of Special Electromechanical Technology, Beijing 100012, China \\ ${ }^{4}$ The 713 Research Institute of CSIC, Zhengzhou 450015, China
}

Correspondence should be addressed to Junli Han; mzztmn@126.com

Received 15 September 2021; Accepted 25 October 2021; Published 8 December 2021

Academic Editor: Jinyang Xu

Copyright (c) 2021 Tianpeng Li et al. This is an open access article distributed under the Creative Commons Attribution License, which permits unrestricted use, distribution, and reproduction in any medium, provided the original work is properly cited.

To describe the effect of confining pressure on the mechanical responses of N15 propellant, a constitutive model considering the confining pressure effect was first established for N15 propellant based on the elastic-viscoelastic correspondence principle. Then, the mechanical properties of N15 solid propellant under different confining pressures were obtained using confining pressure test system, and the obtained results indicate that the initial modulus of propellant did not change with confining pressure, but the maximum tensile strength, rupture strength, the maximum elongation, and elongation at break increased with increasing confining pressure. In conjunction with propellants' mesoscopic structure and cross-section analysis, the mechanical mechanism of confining pressure effect on propellant was initially disclosed. Due to confining pressure, the particle dewetting inside the propellant was reduced, the hole propagation was delayed, and crack extension inhibited germination, proving that confining pressure has a strengthening impact on the propellant. Finally, assuming that the model parameters were dependent on pressure, the model parameters acquisition and validation were conducted. The results demonstrated that constitutive model can describe confining pressure influence on the mechanical properties of N15 propellant accurately.

\section{Introduction}

The mechanical properties of solid propellants under complex loads are essential as a support and basis to study charge structure integrity. Based on previous researches [1-3], engine ignition and pressurization process is a weak link in charge structure failure. During engine ignition, the internal pressure of the combustion chamber is as high as $10 \mathrm{MPa}$, and the charge structure, especially the charge column, is exposed to high temperature and high-pressure environments. The mechanical properties of solid propellants in this complex state vary from those at room temperature and atmospheric pressure. A solid propellant material is considered to be incompressible, and the axial and radial strains of the column demonstrate compressive strain in the confining pressure environment. However, in the circumferential direction, the solid propellant material is in three directions. The study of the mechanical properties of solid propellants is carried out under atmospheric pressure [4]. By studying the nonlinear mechanical properties of composite solid propellants, a damage-containing thermoviscous elastic constitutive model was established, and the material function at different temperatures was unified to a reference temperature using conversion time. The model was first proposed as a one-dimensional form [5] and quickly expanded into a three-dimensional form [6]. The three-dimensional constitutive model was developed and applied to the finite element software ABAQUS, and the mechanical response of HTPB propellant with $70 \%$ particle volume fraction was successfully simulated under uniaxial and multiaxial complex stress conditions. On the domestic side, a few nonlinear viscoelastic constitutive models of composite solid propellant under atmospheric pressure were also proposed by $\mathrm{Xu}$ et al. [7], Peng et al. [8], and Ma et al. [9].

However, a solid propellant is a kind of viscoelastic material with pressure sensitivity. It is unreasonable to study 
the structural integrity of charge under ignition and pressurization using propellant mechanical characteristics under atmospheric pressure. This may be the reason that the mechanical properties of the charge meet the design index at atmospheric pressure, but frequent failure accidents occur in the ignition. Therefore, the mechanical properties of propellants under confining pressure must be studied in detail.

A few research work have been carried out on viscoelastic materials' mechanical properties under confining pressure. Sridhar and Fleck [10] and Peroni et al. [11] studied hydrostatic pressure impact on the mechanical properties of aluminum foam materials. The analysis of the stress state around the particles filled with solid propellant under confining pressure by Liu et al. [12] showed that (1) there is a high triaxial tensile stress on particles surface at ambient pressure or external pressure, and (2) under ambient pressure, tensile stress surrounds the high triaxial tensile stress region, while the compressive stress surrounds the high triaxial tensile stress region under external pressure. The initiation and evolution of damage are inhibited, and the material has higher strength and modulus. The uniaxial tensile and shear tests of propellants under different confining pressures $(0 \sim 15 \mathrm{MPa})$ were carried out [13]. It was found that the confining pressure environment significantly increased the failure stress and failure strain of propellant. Özüpek [14] found that the confining pressure environment has little effect on propellant mechanical properties before "dewetting," but it could greatly affect its failure parameters.

In the finite strain model framework of Simo [15], Tunç, and Özüpek [16, 17] developed the three-dimensional viscoelastic constitutive model under confining pressure environment by introducing the damage evolution model of Canga et al. [18] and carried out the finite element secondary development to expand the application. A confining pressure test system with hydraulic oil as a pressurized medium was designed to study the effect of confining pressure on doublebase propellant mechanical properties [19]. Also, following the finite strain framework of Simo, Kumar et al. [20, 21] adopted two kinds of dilatational strain energy models to model the effect of confining pressure. The wide temperature-gas confining pressure test system was developed by Zhang et al. [22], a high-pressure gas was used to form the confining pressure environment, and the temperature of highpressure gas and propellant samples was controlled by convection heat transfer. Bihari et al. [23] pointed that the strain capability of HTPB propellant increased as the strain rate at a given pressure increased, and the maximum stress capability was in the pressure range of 4 to $6 \mathrm{MPa}$.

To sum up, a series of studies have been carried out on propellant mechanical characteristics under confining pressure environment during past decades. However, these work focus on the HTPB propellant, and comparing to the recent solid propellant, the deformation is relatively small. Meantime, these models need the dilatational volume to determine the model parameters and the ability to describe large deformation response of recent solid propellant has not been proved. Therefore, the mechanical properties and corresponding constitutive model of solid propellant should be carried out.
In this paper, we introduced a nonlinear viscoelastic constitutive model to model the effect of confining pressure and the method of model parameters acquisition was presented. The mechanical properties of N15 solid propellants under confining pressure were obtained and analyzed. The ability of the nonlinear constitutive model to describe the stress-strain responses of N15 propellant was validated. It is believed that this work will lay a foundation for analyzing the structural integrity of charge under the ignition shock and pressure load of a solid rocket engine.

\section{Constitutive Model}

2.1. Constitutive Model Theory. In order to build a relationship between mechanical states of elastic and viscoelastic media, Schapery [24] proposed the concept of pseudovariable and developed for constitutive equations of nonlinear viscoelastic materials. Corresponding to the stress-strain relationship of elastic materials, for viscoelastic materials, the definition is as follows:

$$
\varepsilon^{R} \equiv \frac{1}{E_{R}} \int_{0}^{t} E(t-\tau) \frac{d \varepsilon}{d \tau} d \tau
$$

In the formula, $\varepsilon^{R}$ is the pseudostrain, $E_{R}$ is the reference elastic modulus, usually taken as $E_{R}=1$, and the relaxation modulus function of viscoelastic material is $E(t)$. Then, the relaxed integral viscoelastic constitutive model can be written

$$
\sigma=E_{R} \varepsilon^{R}
$$

Generally, under small deformation, the mechanical responses of solid propellant can be described by the linear viscoelastic model theory (equation (2)), and as the strain and stress increase, damage (e.g., deweeting and microcrackes) would generated inside propellant, and a damage function is essential to describe the degradation of mechanical properties at this stage. Therefore, a damage function $C(S)$ is introduced when there is damage inside the viscoelastic body, and the upper formula can be rewritten to

$$
\sigma=C(S) \cdot E_{R} \cdot \varepsilon^{R}
$$

The pseudostrain energy density function is

$$
W_{R}\left(\varepsilon^{R}, S\right)=C(S) \frac{\left(\varepsilon^{R}\right)^{2}}{2}
$$

Considering the local crack growth obeys a power law in energy, the damage evolution law can be expressed [25]

$$
\dot{S}=\left(-\frac{\partial W_{R}}{\partial S}\right)^{\alpha}
$$

Based on the equation (3), the damage evolution law of 
the material can be changed into

$$
\dot{S}=\left(-\frac{\left(\varepsilon^{R}\right)^{2}}{2} \frac{\partial C(S)}{\partial S}\right)^{\alpha}
$$

If the data acquisition frequency is high, the time increment step $\Delta t$ is small, and the derivative of the damage internal variable $S$ to the time $t$ and the derivative of the damage function $C(S)$ to the internal variable $S$ can be expressed in the form of increment:

$$
\frac{\Delta S}{\Delta t} \approx\left(-\frac{\left(\varepsilon^{R}\right)^{2}}{2} \frac{\Delta C(S)}{\Delta S}\right)
$$

Then, the incremental form $\Delta S$ of the damage internal variable $S$ is

$$
\begin{gathered}
\Delta S=\left(-\frac{\left(\varepsilon^{R}\right)^{2}}{2} \Delta C(S)\right)^{\frac{\alpha}{1+\alpha}} \Delta t^{\frac{1}{1+\alpha}}, \\
S(t+\Delta t)-S(t)=\left(-\frac{\left(\varepsilon^{R}\right)^{2}}{2}(C(t+\Delta t)-C(t))\right)^{\frac{\alpha}{1+\alpha}} \Delta t^{\frac{1}{1+\alpha}} .
\end{gathered}
$$

In equation (8), to characterize the material damage evolution law, the value of material constant at different tensile rates is considered as invariant, related to the creep and relaxation characteristics of the material, and has the following similar relations:

$$
\begin{gathered}
\alpha=1+\frac{1}{n}, \\
n \approx \frac{\log D(t)}{\log t}=-\frac{\log E(t)}{\log t},
\end{gathered}
$$

where the creep compliance and relaxation modulus of the material is expressed as $D(t)$ and $E(t)$, respectively.

2.2. Method of Model Parameters Acquisition. The parameters to be determined in the constitutive equation in the previous section are relaxation modulus function $E(t)$, material constant $\alpha$, internal damage variable $S$, and damage function $C(S)$. The acquisition steps of other parameters are described below:

(1) Determine the initial value of the material constant describing the law of damage evolution according to the relaxation modulus in the form of Prony series fitted by relaxation test

(2) According to the theory of linear viscoelasticity and $E_{R}=1$, the corresponding pseudostrain values at different tensile rates are calculated

(3) According to the stress-strain calculation at different tensile rates, the relationship $C(t)$ between damage function $C(S)$ and time $t$ is obtained
(4) Based on equation (8), the function relation $S(t)$ between variable $S$ and time $t$ in damage can be obtained, and the corresponding relation $C(t)$ can be formed with the function obtained in step 3 , and the function $C(S)$ can be obtained

(5) The function curves $C(S)$ obtained under different tensile rates of the same ambient pressure are plotted in the same coordinate system. If the coincidence degree of each curve is poor, adjust the material constant value appropriately, and repeat steps 4 and 5 .

(6) According to step 5, the final function curve $C(S)$ is obtained, and then the function $C(S)$ is fitted

(7) Following the same fitting processes, the function $C(S)$ can be determined for various confining pressure conditions, and the material parameters and fitted parameters are considered as pressure-dependent. Finally, the constitutive model considering the effect of confining pressure can be developed.

The fitting flow chart of each parameter is shown in Figure 1:

\section{Experimental Research and Discussions}

3.1. Compass Test System. The confining pressure test system consists of three parts: pressure supply device, confining pressure device, and loading device. The pressure supply device is used to supply high-pressure gas required in the test, and the confining pressure device takes the closed cylinder block, which is resistant to high pressure as the main body to provide high-pressure gas environment required during the test and keeps the pressure stable in the cylinder. The detailed installation of the confining pressure device is shown in Figure 2.

\subsection{Test Program}

3.2.1. Test Material. N15 propellant is a particle-filled highenergy composite material, which is usually adjusted according to different application indexes to meet the demand for its combustion or energy characteristics. Because of the influence of processing flow and environmental factors, the internal structure state is uneven, while propellant microstructure is not different, and the macroscopic mechanical properties are basically unchanged. A certain formula of the same batch N15 cast propellant embryo is selected as the research object in this paper. The basic formula is shown in Table 1. Referring to the standard of the tensile test method of solid propellant QJ924-85, N15 propellant embryo material is cut and machined into dumbbell specimen with specific size as demonstrated in Figure 3(a). The specimen is put into the incubator after processing and kept in a constant temperature environment of $50^{\circ} \mathrm{C}$ for $24 \mathrm{~h}$ and then cooled naturally to eliminate the residual stress produced inside the specimen during machining. The test fixture adopts the standard QJ924-85 recommended tensile test fixture, as displayed in Figure 3(b).

3.2.2. Relaxation Test. The relaxation test was carried out on QJ211B electronic universal testing machine at room temperature $\left(20 \pm 1^{\circ} \mathrm{C}\right)$. The strain level should be selected in the relaxation test when the propellant material is in the linear viscoelastic stage. At this time, the propellant has not suffered any damage, such as dewetting and interchain sliding fracture; so, 


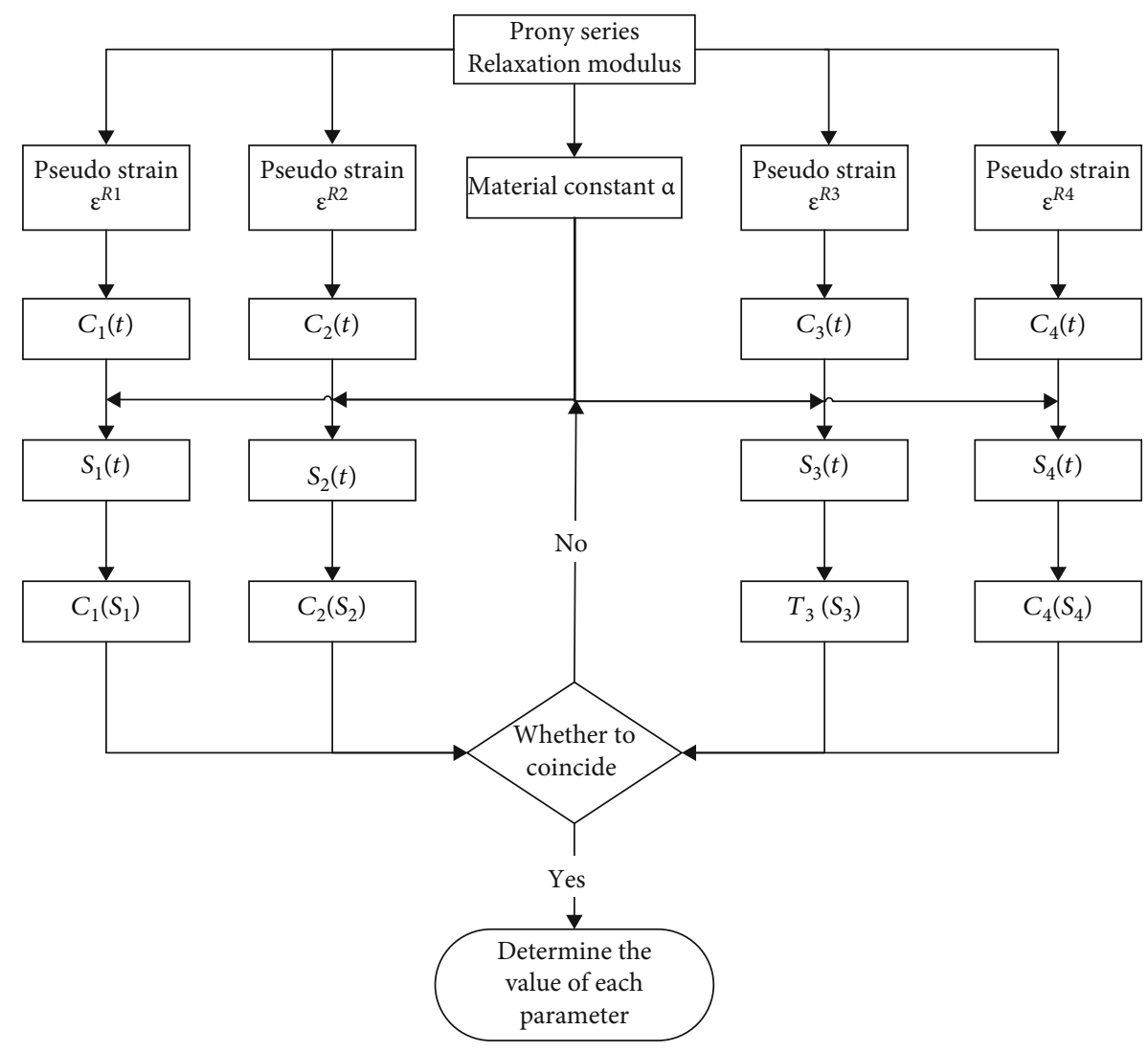

FIGURE 1: Flowchart of constitutive model parameter fitting.

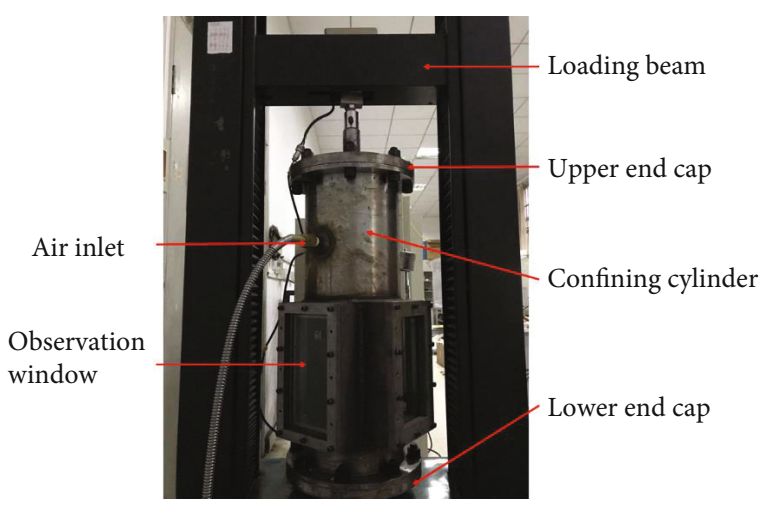

Figure 2: Physical diagram of the confining pressure device.

TABLE 1: N15 Solid propellant base formula.

\begin{tabular}{lccccc}
\hline Adhesive/\% & Plasticizer/\% & $\mathrm{AP} / \%$ & $\mathrm{Al} / \%$ & $\mathrm{RDX} / \%$ & Catalyst $/ \%$ \\
\hline $6 \sim 8$ & $17 \sim 21$ & $20 \sim 30$ & $20 \sim 30$ & $18 \sim 20$ & $1 \sim 3$ \\
\hline
\end{tabular}

the accuracy of the obtained propellant relaxation modulus can be guaranteed. The strain level is $8 \%$, and the equivalent rate linear loading process is selected for strain loading. The tensile rate of the specimen is $100 \mathrm{~mm} / \mathrm{min}$ to $4 \mathrm{~mm}$ (the standard distance of the specimen is $50 \mathrm{~mm}$ ). After the strain level is reaches $8 \%$, the stress response of the specimen is stopped and recorded in real-time. The relaxation time is $3600 \mathrm{~s}$. Under this condition, repeated tests are carried out many times, the test is terminated when test data repeatability is good, and the average value is taken as the final test result.

3.2.3. Uniaxial Tensile Test. Under uniaxial tensile test, to analyze the mechanical properties of $\mathrm{N} 15$ propellants under different pressures, four groups of pressure environments were selected for testing: $0,0.5,2$, and 5.4 $\mathrm{MPa}$ (apparent pressure). Uniaxial tensile tests of 4 rates at each pressure value were carried out. The tensile rates were $2,10,50$, and $200 \mathrm{~mm} / \mathrm{min}$, and corresponding strain rates were $0.000667,0.00333,0.0167$, and $0.0667 \mathrm{~s}^{-1}$, respectively. The detailed experimental plan is listed in Table 2 . This testing scheme not only studies the effect of different tensile rates on mechanical properties of N15 propellants under the same pressure environment but also investigates the effect of different environmental pressures on the mechanical behavior of $\mathrm{N} 15$ propellants at the same tensile rate. The scheme comprises 16 working conditions, three repeated tests are conducted under each working condition, and the total number of tests is 48 . Because of the difference of propellant material itself, if there is a strange result in the process, the test result should be abandoned and repeated to ensure three test data with good repetition under each working condition. The average value of three groups of test data is chosen as the final test result.

\subsection{Test Results}

3.3.1. Relaxation Test. The relaxation test results are depicted in Figure 4 . In the early stage of relaxation $(0 \sim 1000 s)$, N15 


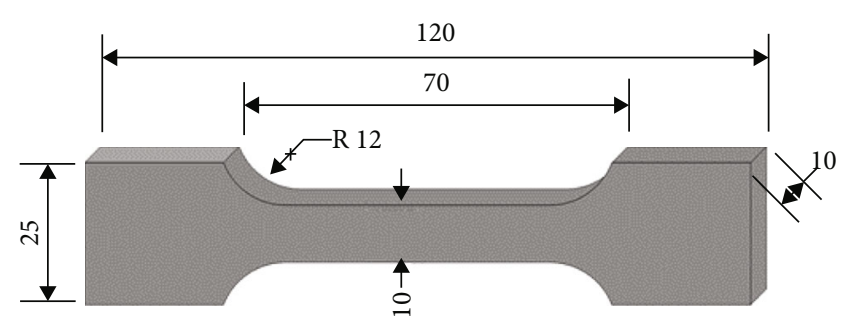

(a) Size of dumbbell specimens

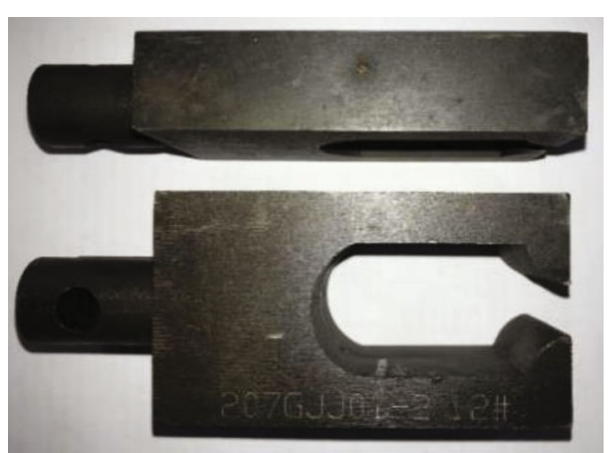

(b) Specimen fixture

FIgURE 3: The propellant specimen size and fixture.

TABle 2: The detailed experimental plan.

\begin{tabular}{lcc}
\hline $\begin{array}{l}\text { Test } \\
\text { temperature } /{ }^{\circ} \mathrm{C}\end{array}$ & $\begin{array}{c}\text { Tensile speed/ } \\
(\mathrm{mm} / \mathrm{min})\end{array}$ & $\begin{array}{c}\text { Confining pressure/MPa } \\
\text { (relative atmospheric pressure) }\end{array}$ \\
\hline \multirow{2}{*}{20} & 2 & $0,0.5,2,5.4$ \\
& 10 & $0,0.5,2,5.4$ \\
& 50 & $0,0.5,2,5.4$ \\
& 200 & $0,0.5,2,5.4$ \\
\hline
\end{tabular}

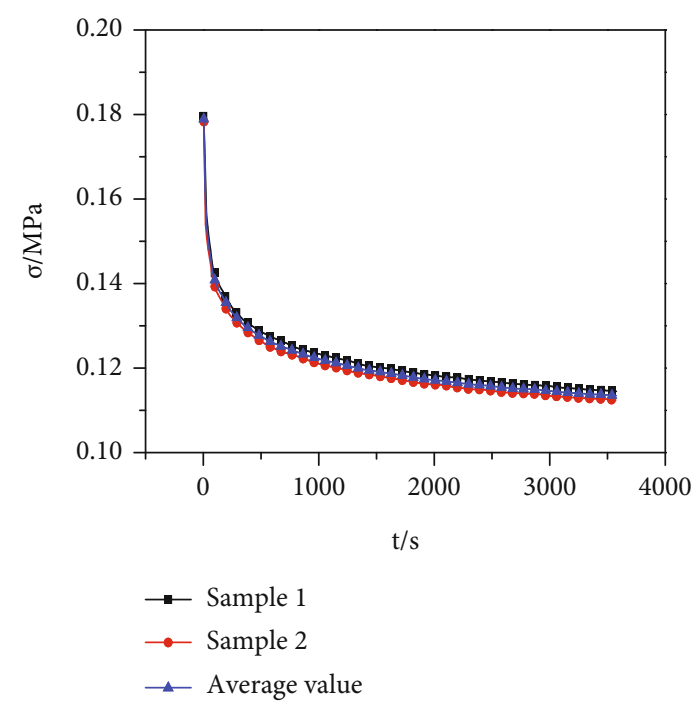

Figure 4: Test results of N15 propellant relaxation at room temperature.

propellant stress decreases rapidly with time. After $2000 \mathrm{~s}$, the specimen enters the stable stage, and the stress tends to stabilize gradually, consistent with the stress relaxation phenomenon of viscoelastic materials mentioned above.

According to relaxation test results, relaxation modulus $E(t)$ decreases in logarithmic order with time. According to experimental results, the relaxation modulus function of the 7th order Prony series is as follows:

$$
\begin{aligned}
E(t)= & 1.3518+26.5316 e^{-\frac{t}{0.001}}+13.1452 e^{-\frac{t}{0.01}}+7.9518 e^{-\frac{t}{0.1}} \\
& +3.5226 e^{-t}+2.9025 e^{-\frac{t}{10}}+1.5485 e^{-\frac{t}{100}}+0.4591 e^{-\frac{t}{1000}}
\end{aligned}
$$

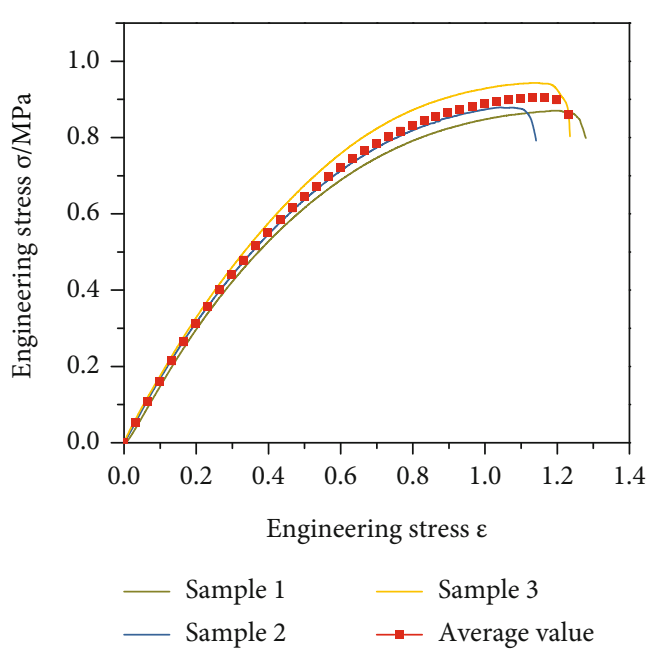

FIgURE 5: Uniaxial tensile stress-strain curves (2 MPa, $10 \mathrm{~mm} / \mathrm{min}$ ).

3.3.2. Uniaxial Tensile Test. Under environmental pressure of $2 \mathrm{MPa}$ and a tensile rate of $10 \mathrm{~mm} / \mathrm{min}$, the test data are processed after three repeated tests. As demonstrated in Figure 5, engineering stress-strain curves of the three samples basically coincide, with a better degree in the initial section of the curve, and some differences are found between the equilibrium section and descending section of the curve, which may be caused by measurement error or uneven internal structure of the specimen.

As mentioned above, all the test data are processed and drawn into engineering stress-strain curves under different environmental pressures at the same tensile rate, as shown in Figure 6. In this figure, the engineering stress-strain curve has obvious viscoelastic characteristics, and the initial sections of each curve exhibit linear growth and then enter the yield section, and fracture failure occurs after the strain strengthening section.

Increasing the confining pressure exhibits little impact on the initial modulus of material but prolongs the linear elastic stage of the curve, causing the yield section of the curve to recede, and the maximum tensile and fracture strength of the sample increases by varying degrees. Maximum elongation and elongation at break also increase with 


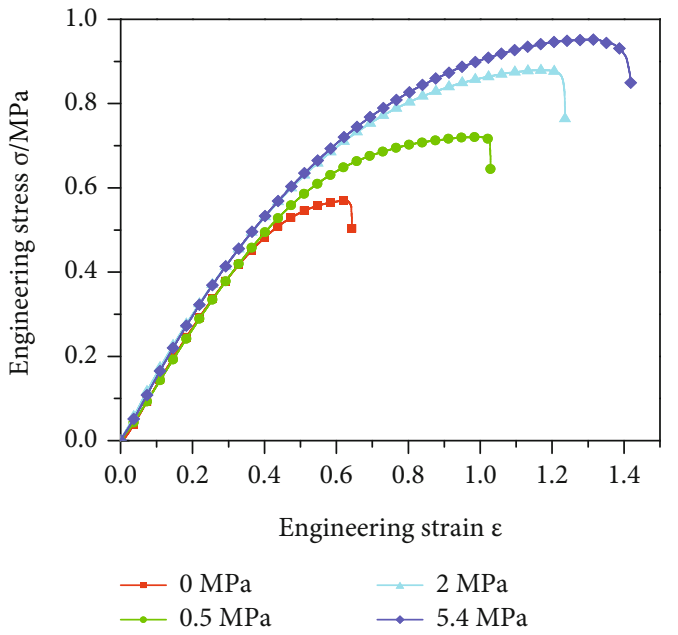

(a) $2 \mathrm{~mm} / \mathrm{min}$

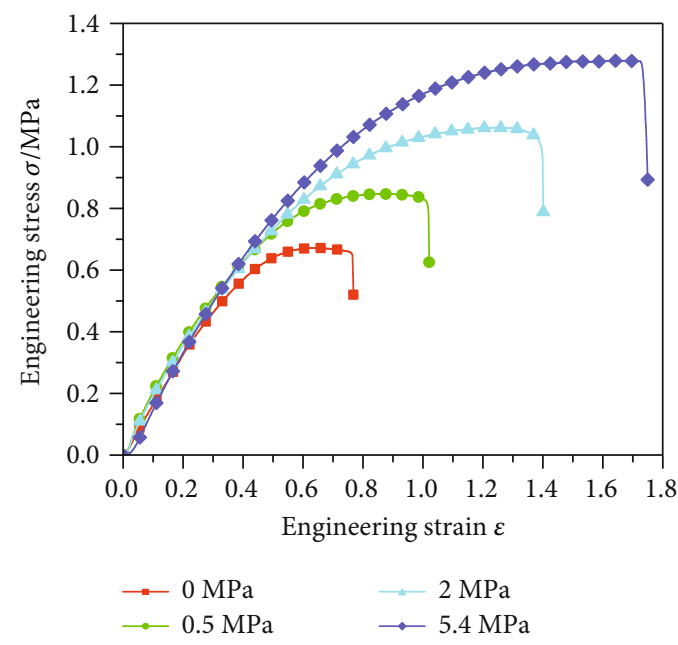

(c) $50 \mathrm{~mm} / \mathrm{min}$

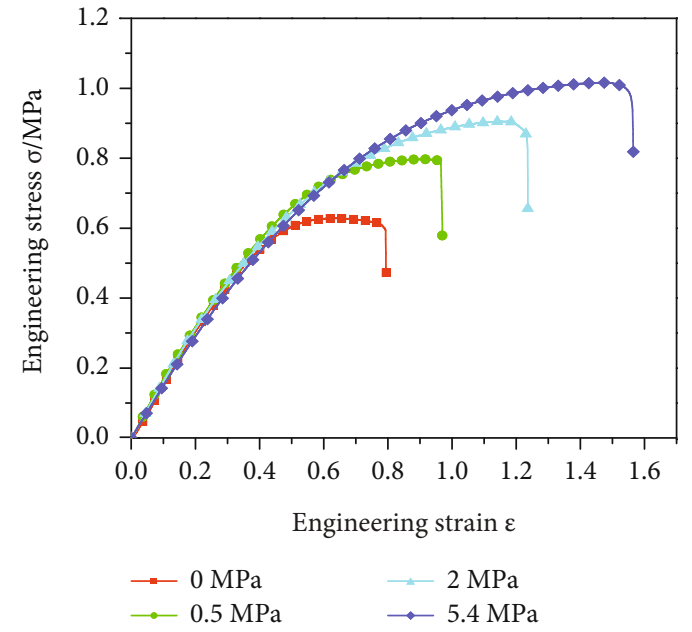

(b) $10 \mathrm{~mm} / \mathrm{min}$

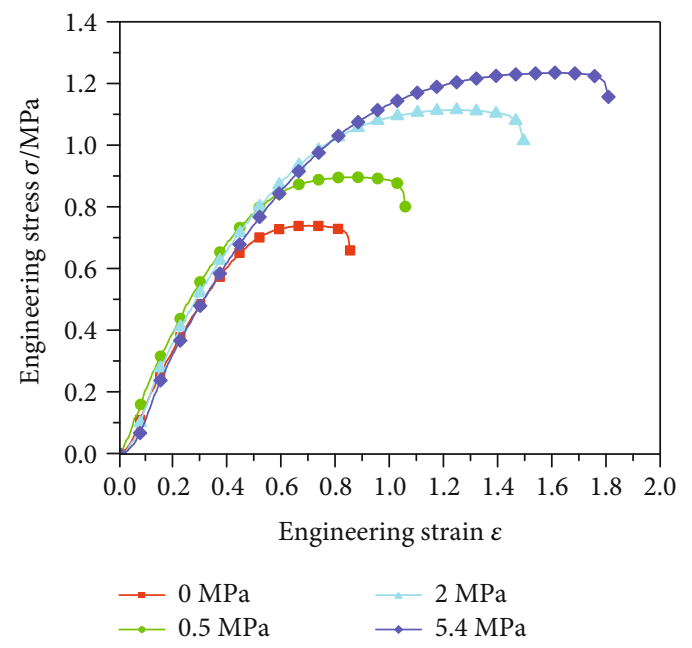

(d) $200 \mathrm{~mm} / \mathrm{min}$

FiguRE 6: Stress-strain curves of N15 propellant under different confining pressures.

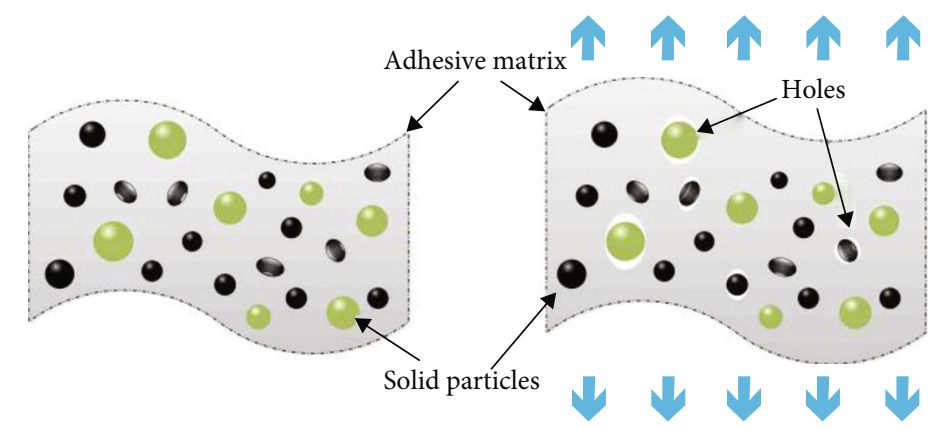

FIGURE 7: Schematic diagram of the propellant microstructure.

environmental pressure, which are different from the results of HTPB propellant $[22,23]$. This may be caused by the particles' size and compositions [22]. Nevertheless, in generally speaking, compression has a strengthening effect on N15 propellants and increases the mechanical properties with enhanced effect in a low confining pressure environment. When the pressure rises from 0 to $0.5 \mathrm{MPa}$, the mechanical parameters of the material are improved, and the strength- ening effect is weakened in a high confining pressure environment [26]. However, the existence of a pressure threshold makes the relevant mechanical parameters reach the upper limit and no longer increase with pressure.

3.4. Effects of Compression Effect on Mechanism. N15 propellant is a high-energy polymer based on a binder and filled with several solid particles. The schematic diagram of 


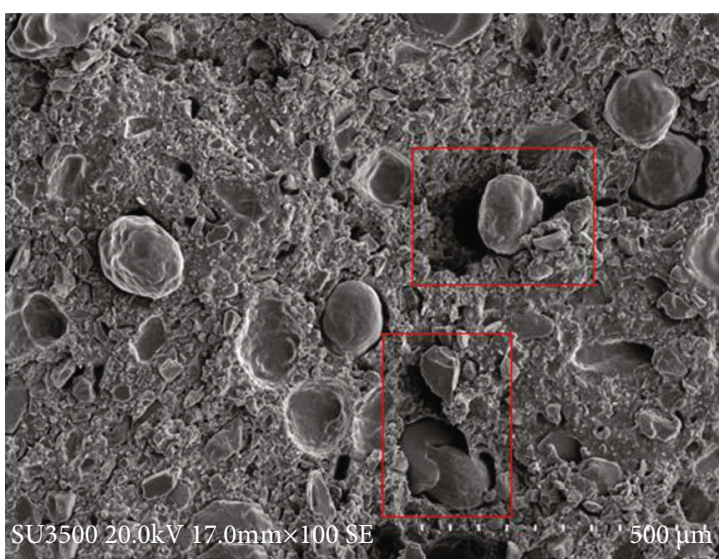

Magnify 100 times

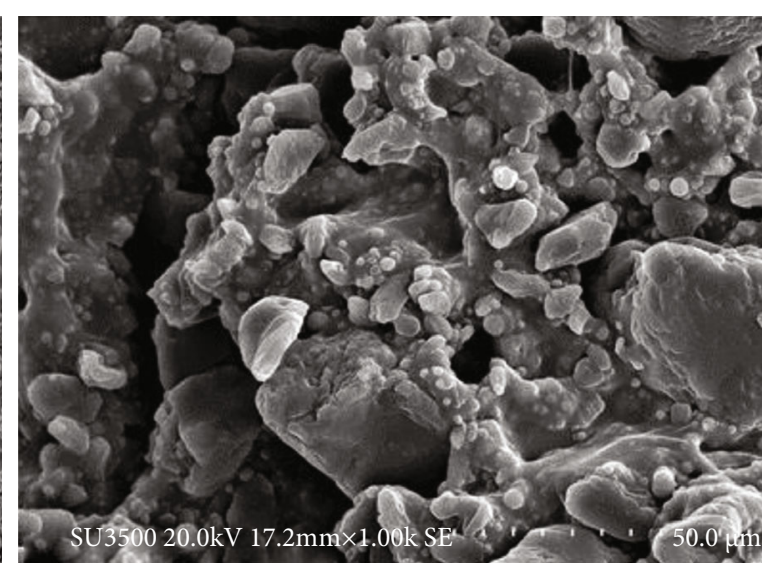

Magnify 1000 times

(a) Environmental pressure $0 \mathrm{MPa}$ and tensile rate $2 \mathrm{~mm} / \mathrm{min}$

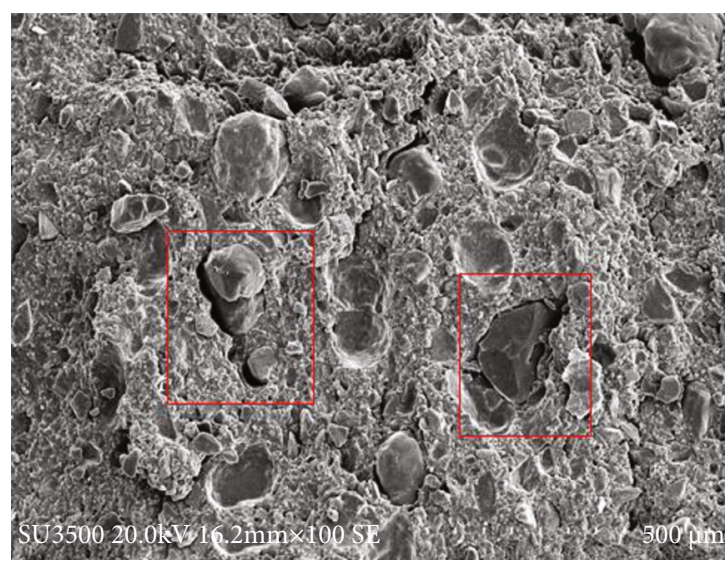

Magnify 100 times

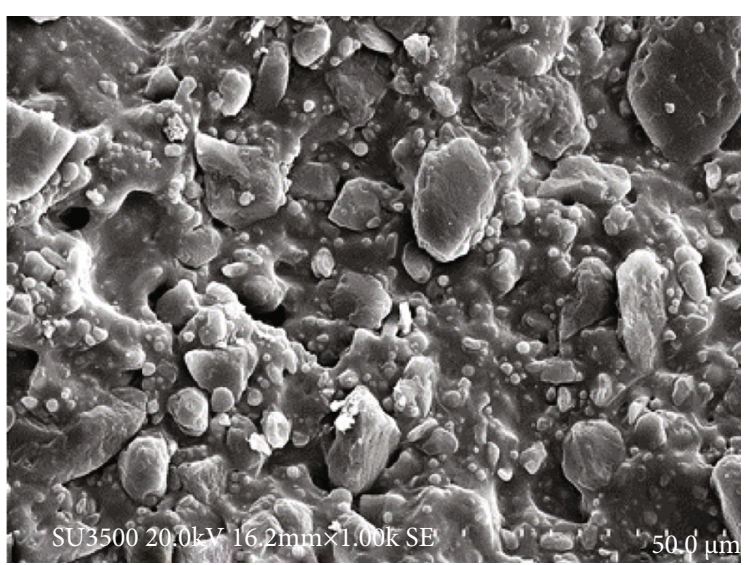

Magnify 1000 times

(b) Environmental pressure $2 \mathrm{MPa}$ and tensile rate $2 \mathrm{~mm} / \mathrm{min}$

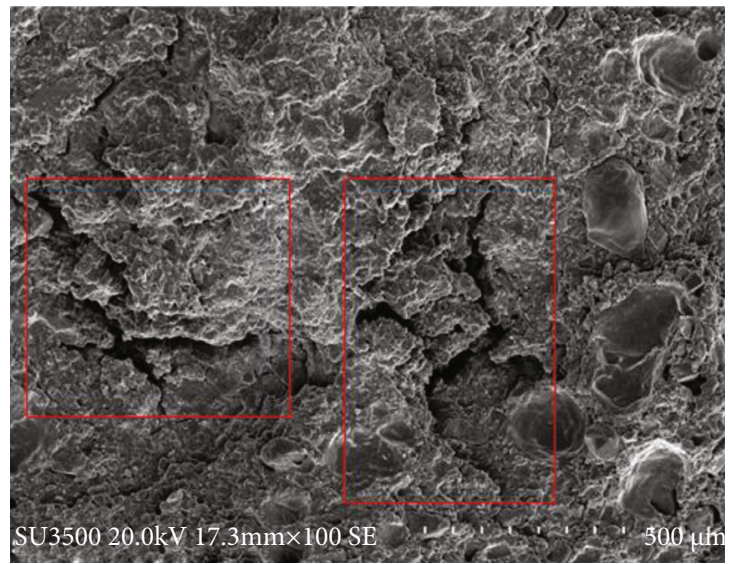

Magnify 100 times

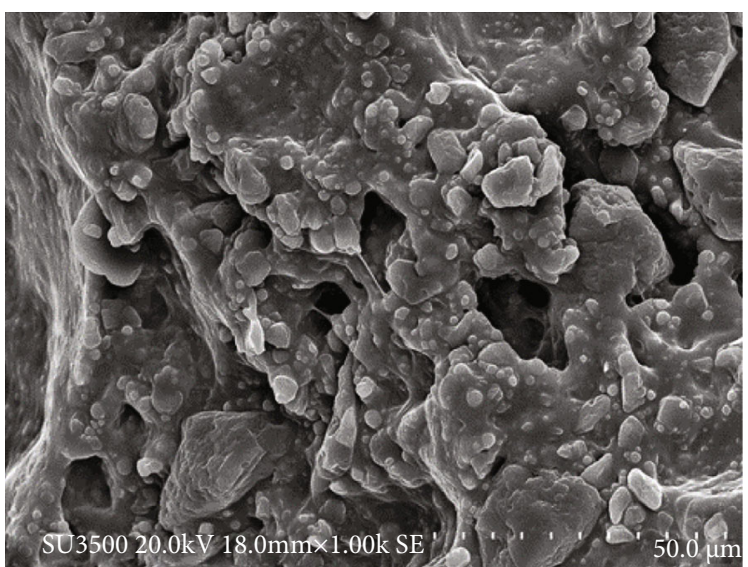

Magnify 1000 times

(c) Environmental pressure $0 \mathrm{MPa}$ and tensile rate $200 \mathrm{~mm} / \mathrm{min}$

Figure 8: Continued. 


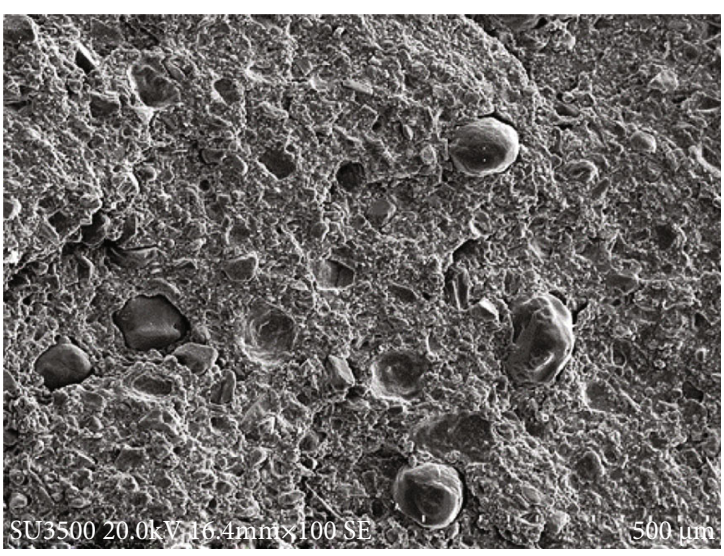

Magnify 100 times

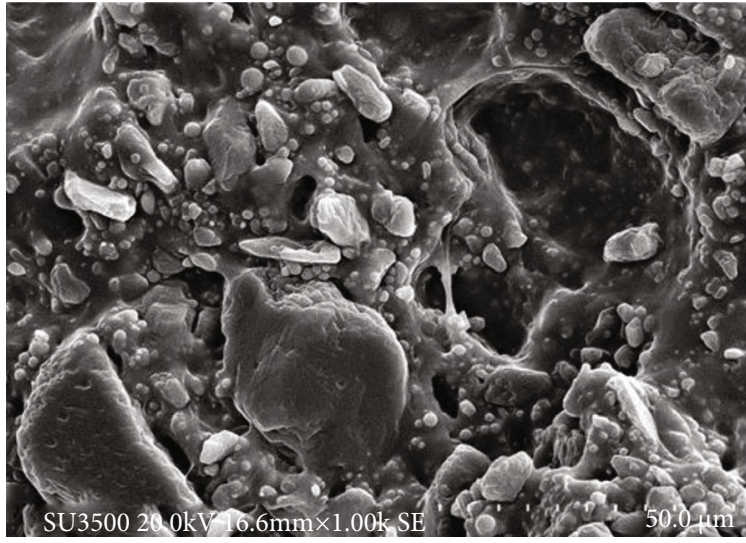

Magnify 1000 times

(d) Environmental pressure $2 \mathrm{MPa}$ and tensile rate $200 \mathrm{~mm} / \mathrm{min}$

FIgURE 8: N15 profile of propellant.
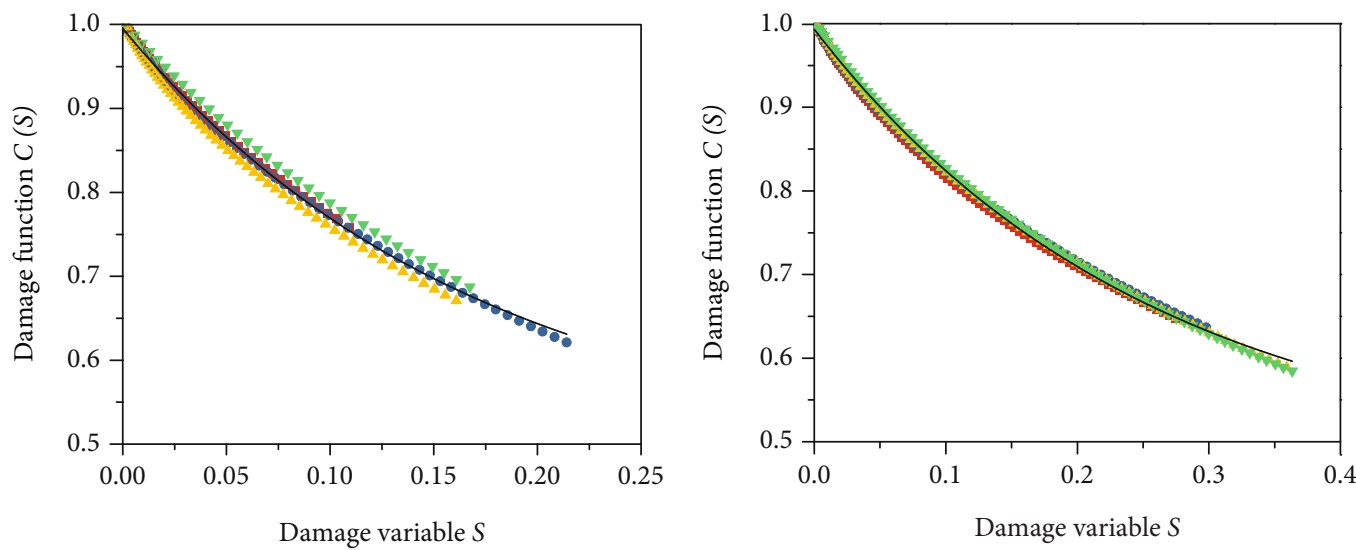

$2 \mathrm{~mm} / \mathrm{min}$
- $10 \mathrm{~mm} / \min \quad 200 \mathrm{~mm} / \mathrm{min}$
$\Delta \quad 50 \mathrm{~mm} / \mathrm{min}$

(a) $0 \mathrm{MPa}$

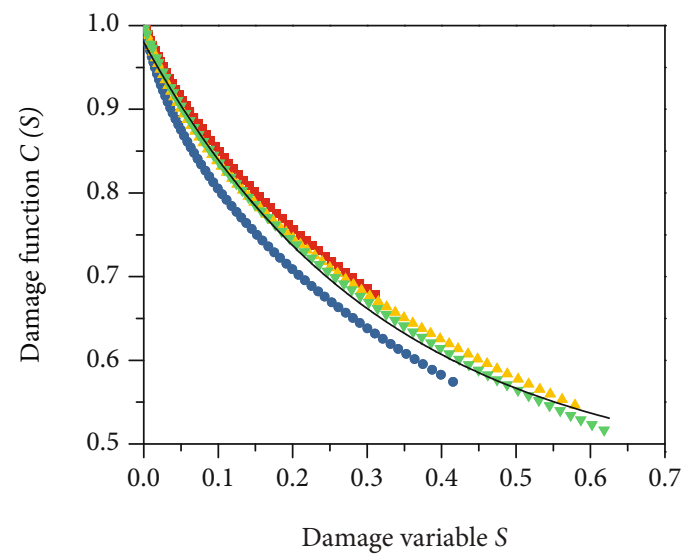

$2 \mathrm{~mm} / \mathrm{min}$
- $10 \mathrm{~mm} / \mathrm{min} \quad \begin{aligned} & 200 \mathrm{~mm} / \mathrm{min} \\ & \Delta\end{aligned} \quad$ Fitted

(c) $2 \mathrm{MPa}$

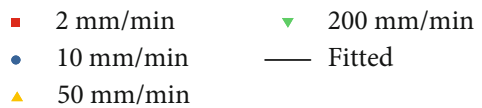

(b) $0.5 \mathrm{MPa}$

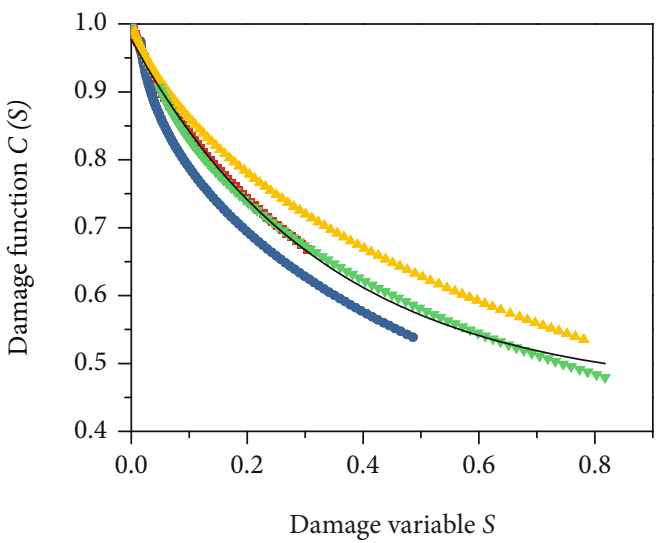

$2 \mathrm{~mm} / \mathrm{min}$
- $10 \mathrm{~mm} / \mathrm{min}$
$\Delta 0 \mathrm{~mm} / \mathrm{min}$$\quad \begin{aligned} & 200 \mathrm{~mm} / \mathrm{min} \\ & \text { Fitted }\end{aligned}$

(d) $5.4 \mathrm{MPa}$

Figure 9: Graphs of environmental pressures $C(S)$. 


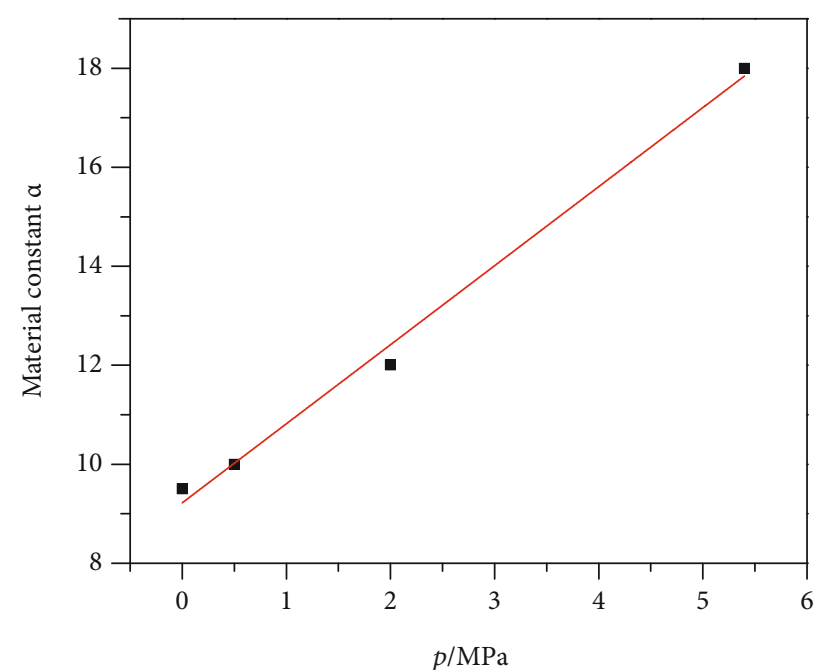

(a) The values of material constant $\alpha$

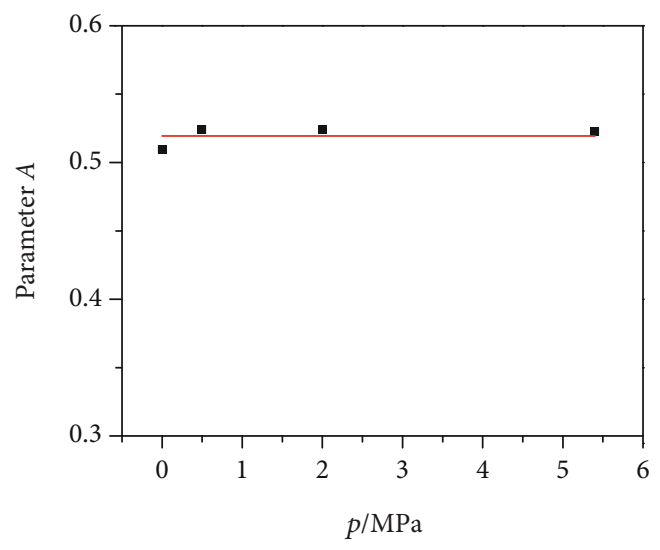

(c) The values of parameter $A$

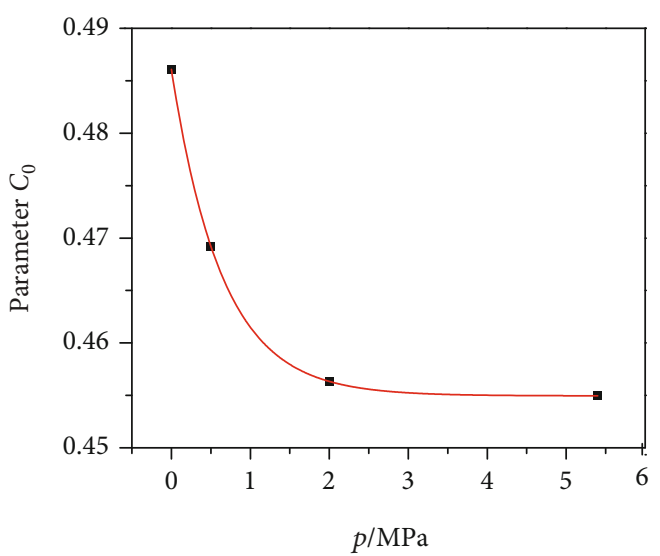

(b) The values of parameter $C_{0}$

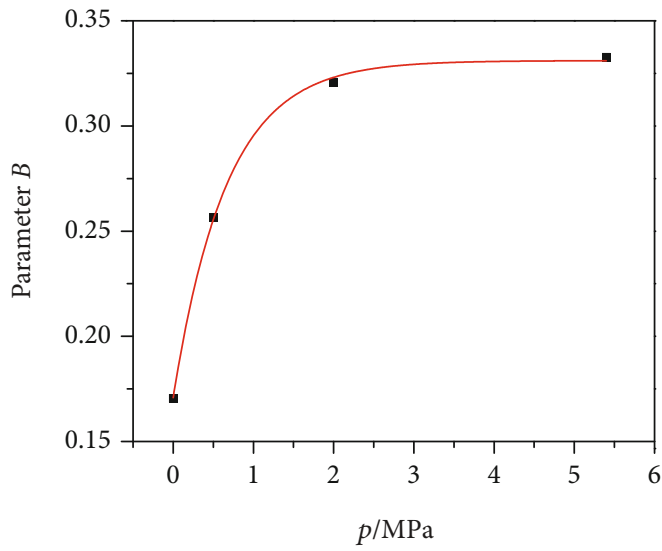

(d) The values of parameter $B$

FIGURE 10: Model parameter fitting results.

propellant microstructure is shown in Figure 7. The mesostructure of the material has a direct effect on its macroscopic mechanical properties. In the multicomponent viscoelastic material, an obvious interface is found between matrix (continuous phase) and solid particles (dispersed phase), and the mesostructure distribution is not uniform, indicating that N15 propellants belong to heterogeneous ones.

A SU 3500 scanning electron microscope was employed to scan and observe the cross-section morphology of the propellant, and the cross-section morphology was obtained, as presented in Figure 8.

Under a tensile rate of $2 \mathrm{~mm} / \mathrm{min}$, compared with 0 and $2 \mathrm{MPa}$ environmental pressures, the cross-section morphology is enlarged by 100 times. From Figure 8(a), an apparent particle dehumidification phenomenon was observed on a cross-section at $0 \mathrm{MPa}$, cracks in the joint surface are formed, and more holes are distributed due to the complete separation of particles and matrix. At $2 \mathrm{MPa}$, dehumidification phenomenon is also found on the section, but forming hole size is less than $0 \mathrm{MPa}$ verified from the enlarged 1000 times morphology diagram, and $2 \mathrm{MPa}$ is higher than $0 \mathrm{MPa}$ when the section is denser, resulting in holes and cracks that are also significantly reduced, as shown in Figure 8 (b). When the tensile rate is $200 \mathrm{~mm} / \mathrm{min}$, the section under $0 \mathrm{MPa}$ has a crack of propagation and fusion but compared with $2 \mathrm{~mm} / \mathrm{min}$ tensile conditions, and there is no evident particle dewetting phenomenon that may be due to the fast tensile rate, seen in Figure 8(c). It can be explained that the environmental pressure affects the internal fracture evolution mechanism of the propellant during the tensile process, which shows that particle dehumidification degree on the section decreases, and the germination and propagation process of microcracks and microspore holes is delayed.

The ambient pressure effects on propellants' mechanical properties can be summarized as follows: ambient pressure acts directly on propellants' surface, compacting the matrix and particles. The propellant specimens are under threedirection compression at first. During propellants being stretched, propellants' internal structure should be dehumidified, whereas microcracks and microholes should be germinated compared with that of propellants at atmospheric pressure. Due to external pressure, the matrix and particles are compressed, which cannot produce particle dewetting, 


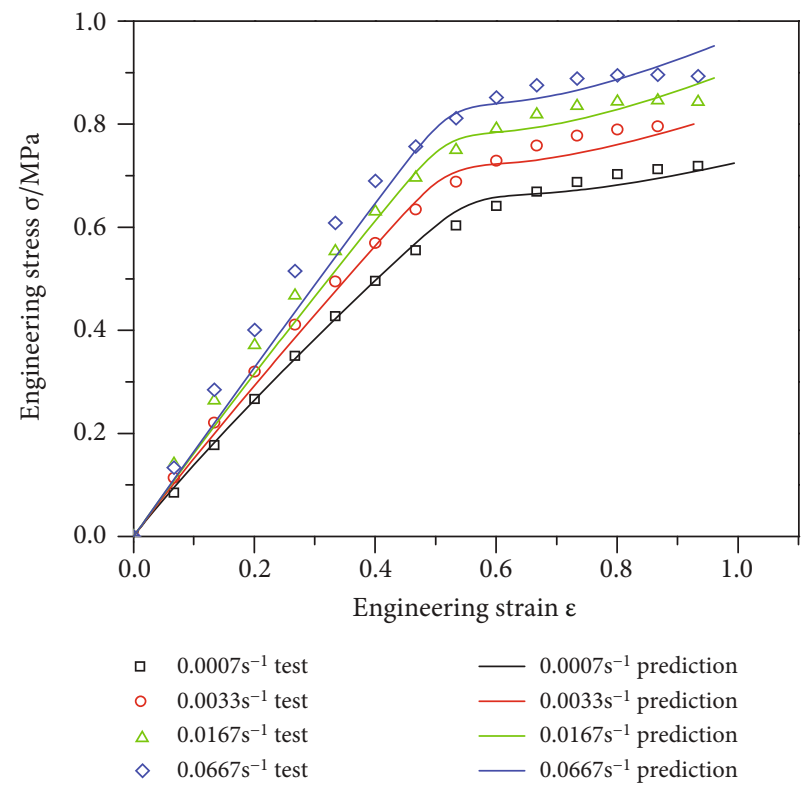

(a) Environmental pressure $0.5 \mathrm{MPa}$

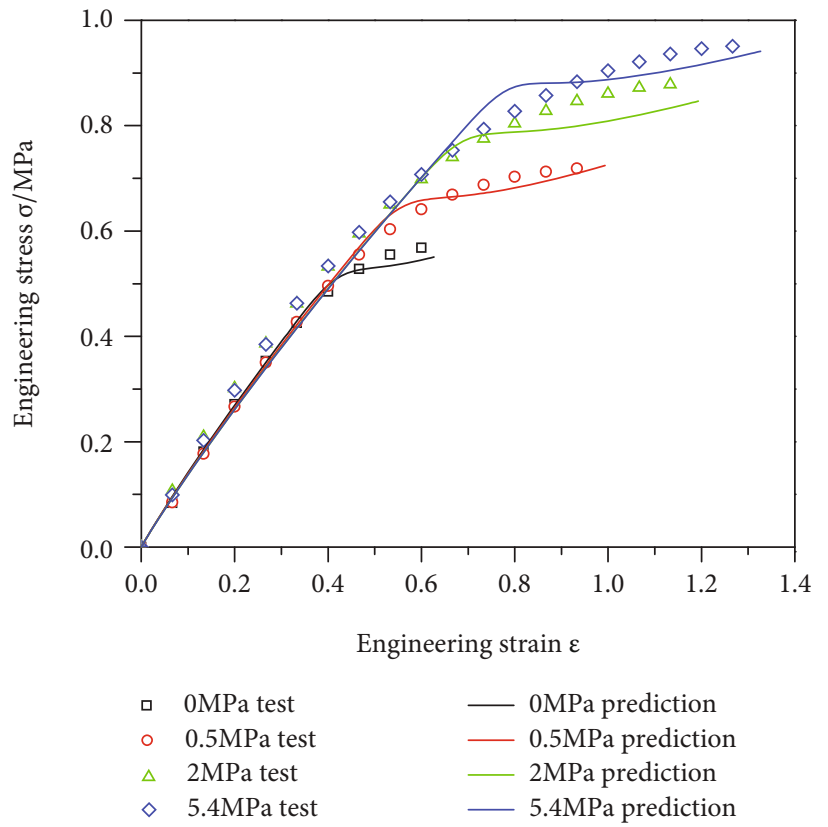

(b) Tensile rate $2 \mathrm{~mm} / \mathrm{min}$

FIgURE 11: Comparison of the model predictions and experimental results.

inhibiting germination of internal cracks and pores, and thus delays their fusion development, and the compactness of propellants is greatly improved [12]. The macroscopic results show that the yield section of the stress-strain curve is delayed, mechanical properties of each material are related to the environmental pressure, and propellant mechanical properties are strengthened.

\section{Model Parameter Acquisition and Validation}

4.1. Model Parameter Acquisition. According to relaxation modulus $E(t)$ obtained by the relaxation test above, the initial value $\alpha=10$ is selected, and the sum of each working condition $C(t)$ and $S(t)$ is obtained in turn by the above fitting steps. After many iterations, the curves $C(S)$ under each environmental pressure are finally fitted as shown in Figure 9.

The fitting curves $C(S)$ under various environmental pressures can be fitted in the following functional forms:

$$
C(S)=C_{0}+A e^{\left(-\frac{S}{B}\right)}
$$

The damage model parameters $C_{0}, A$, and $B$ are described as the function of environmental pressure $p$, and the model parameters are shown in Figure 10.

$$
\begin{gathered}
\alpha=1.597 p+9.22, \\
C_{0}=0.45+0.03 \exp \left(-\frac{p}{0.64}\right), \\
A=0.52, \\
B=0.33-0.16 \exp \left(-\frac{p}{0.666}\right) .
\end{gathered}
$$

4.2. Model Validation. After obtaining all constitutive model parameters, the mechanical response under different environmental pressure and different strain rates can be calculated and then compared with the test results to verify the model's accuracy.

First, the pseudostrain value is calculated from the known strain rate and relaxation modulus, and then the damage variable $S$ value is calculated, in which the increment form of the damage internal variable is

$$
\Delta S=\left(\frac{\left(\varepsilon^{R}\right)^{2}}{2} \frac{A}{B} e^{-\frac{S}{B}}\right)^{\alpha} \Delta t .
$$

Then, the damage function value $C(S)$ is obtained, and the stress response is calculated. Finally, the complete stress-strain relationship is obtained.

The stress-strain relationship of specimens under different strain rates of $0.5 \mathrm{MPa}$ and tensile rate of $2 \mathrm{~mm} / \mathrm{min}$ is calculated. The calculated results are compared with the test results in Figure 11. The coincidence degree between the calculated result curve and the test curve is better, indicating that the model's accuracy and parameters are better.

\section{Conclusions}

Based on the mechanical properties test and theoretical analysis of N15 solid propellants under different confining pressure conditions, we concluded the following:

(1) The confining pressure exhibits little impact on the propellant's initial modulus but extends the linear elastic stage of the stress-strain curve, causing the yield section of the curve to recede and the 
maximum tensile strength and fracture strength of the specimen augment in varying degrees

(2) The SEM technique was developed to analyze propellant cross-section morphology, and it was found that the internal particle humidity of the propellant decreased due to the confining pressure

(3) The damage viscoelastic constitutive model of N15 propellant considering confining pressure effect is established. The mechanical response under different working conditions is calculated and compared with experimental results. The results show that N15 propellant containing damage viscoelastic constitutive model considering confining pressure effect is precise and can accurately describe confining pressure impact on N15 propellant mechanical properties

\section{Data Availability}

The data used to support the findings of this study are available from the corresponding author upon request (hanjunli3390@sina.com).

\section{Conflicts of Interest}

The authors declare no conflict of interest.

\section{References}

[1] J. S. Xu, Experimental and Numerical Research on ThermoViscoelastic Constitutive Model of Composite Propellants, Nanjing University of Science and Technology, Nanjing, 2013.

[2] J. L. Gong, X. Z. Fan, H. Y. Li, and Z. Wang, “Transient structural integrity analysis of single chamber dual thrust engine charge," Journal of Projectiles, Rockets, Missiles and Guidance, vol. 36, no. 6, pp. 78-82, 2016.

[3] H. L. Wang, J. S. Xu, Z. K. Liu, X. Tong, and C. S. Zhou, "Research on the viscoelasticity-viscoplasticity-viscodamage constitutive model of composite modified double base propellant," Acta Armamentarii, vol. 39, no. 7, pp. 13081315, 2018.

[4] S. W. Park and R. A. Schapery, "A viscoelastic constitutive model for particulate composites with growing damage," International Journal of Solids and Structures, vol. 34, no. 8, pp. 931-947, 1997.

[5] K. Ha and R. A. Schapery, "A three-dimensional viscoelastic constitutive model for particulate composites with growing damage and its experimental validation," International Journal of Solids and Structures, vol. 35, no. 26-27, pp. 3497-3517, 1998.

[6] R. M. Hinterhoelzl and R. A. Schapery, "FEM implementation of a three-dimensional viscoelastic constitutive model for particulate composites with damage growth," Mechanics of TimeDependent Materials, vol. 8, no. 1, pp. 65-94, 2004.

[7] J. S. Xu, X. Chen, H. L. Wang, J. Zheng, and C. S. Zhou, "Thermo-damage-viscoelastic constitutive model of HTPB composite propellant," International Journal of Solids and Structures, vol. 51, no. 18, pp. 3209-3217, 2014.
[8] W. Pei, Research on Micromechanics of Viscoelasticity Damage Constitutive Model of Composite Solid Propellant, National University of Defense Technology, Changsha, 2001.

[9] H. Ma, Z. B. Shen, and D. K. Li, "A viscoelastic constitutive model of composite propellant considering dewetting and strain-rate and its implementation," Propellants, Explosives, Pyrotechnics, vol. 44, no. 6, pp. 759-768, 2019.

[10] I. Sridhar and N. A. Fleck, "The multiaxial yield behaviour of an aluminium alloy foam," Journal of Materials Science, vol. 40, no. 15, pp. 4005-4008, 2005.

[11] L. Peroni, M. Avalle, and M. Peroni, "The mechanical behaviour of aluminium foam structures in different loading conditions," International Journal of Impact Engineering, vol. 35, no. 7, pp. 644-658, 2008.

[12] C. T. Liu, D. Wickham, and G. Smith, "Effects of confining pressure on the crack growth behavior in a filled elastomer subjected to a constant strain rate," in Air Force Research Lab Edwards AFB Ca Space and Missile Propulsion Div, pp. 188193, State of California, US, 2004.

[13] Y. Traissac, J. Ninous, R. Neviere, and J. Pouyet, "Mechanical behavior of a solid composite propellant during motor ignition," Rubber Chemistry \& Technology, vol. 68, no. 1, pp. 146-157, 1995.

[14] S. Özüpek, Constitutive Equations for Solid Propellants, University of Texas at Austin, Texas, 1997.

[15] J. C. Simo, "On a fully three-dimensional finite-strain viscoelastic damage model: formulation and computational aspects," Computer Methods in Applied Mechanics and Engineering, vol. 60, no. 2, pp. 153-173, 1987.

[16] B. Tunç and S. Özüpek, "Constitutive modeling of solid propellants for three dimensional nonlinear finite element analysis," Aerospace Science and Technology, vol. 69, pp. 290-297, 2017.

[17] B. Tunç and S. Özüpek, "Implementation and validation of a three dimensional damaging finite strain viscoelastic model," International Journal of Solids and Structures, vol. 102-103, pp. 275-285, 2016.

[18] M. E. Canga, E. B. Becker, and S. Özüpek, "Constitutive modeling of viscoelastic materials with damage - computational aspects," Computer Methods in Applied Mechanics and Engineering, vol. 190, no. 15-17, pp. 2207-2226, 2001.

[19] J. B. Zhang, Research on the Yield Criterion and ViscoElastoplastic Constitutive Model of the Double-Base Propellant, Nanjing University of Science and Technology, Nanjing, 2013.

[20] N. Kumar, B. P. Patel, V. V. Rao, and B. S. Subhaschandran, "Hyperviscoelastic constitutive modelling of solid propellants with damage and compressibility," Propellants, Explosives, Pyrotechnics, vol. 43, no. 5, pp. 461-471, 2018.

[21] N. Kumar, B. P. Patel, V. V. Rao, and B. S. Subhashchandran, "Compressibility, damage, and age-hardening effects of solid propellants using finite strain constitutive model," Journal of Engineering Materials and Technology, vol. 141, no. 3, 2019.

[22] L. Zhang, Z. B. Shen, and H. Y. Li, "Effects of superimposed pressure on the mechanical properties of htpb propellant in a wide temperature range," Propellants, Explosives, Pyrotechnics, vol. 45, no. 8, pp. 1216-1226, 2020.

[23] B. K. Bihari, A. Kumaraswamy, M. Jain, N. P. N. Rao, and K. P. S. Murthy, "Effect of pressure on mechanical properties of composite propellant," Propellants, Explosives, Pyrotechnics, vol. 46, no. 5, pp. 799-805, 2021. 
[24] R. A. Schapery, "Correspondence principles and a generalizedJ integral for large deformation and fracture analysis of viscoelastic media," International Journal of Fracture, vol. 25, no. 3, pp. 195-223, 1984.

[25] S. W. Park, Development of a Nonlinear Thermo-Viscoelastic Constitutive Equation for Particulate Composites with Growing Damage, The University of Texas at Austin, Austin, 1994.

[26] Z. J. Wang and H. F. Qiang, "Mechanical properties of thermal aged HTPB composite solid propellant under confining pressure," Defence Technology, 2021. 